Highly stable, the compounds persist in soil and water, bioaccumulate, and are found in the blood and tissues of animals and humans. Several PFAS, including perfluorooctanoic acid (PFOA) and perfluorooctanesulfonic acid (PFOS), have been associated with negative health effects through hormone disruption and immunologic dysfunction.

This ongoing study explores the associations between PFAS biomarkers, autoimmunity, and neighborhood-level social determinants of health among African Americans participating in a population-based cohort study.

Methods Data was utilized from a longitudinal study of Gullah African American patients with SLE and non-SLE controls. Demographics, medical history, Social Vulnerability Index (SVI) (incorporating socioeconomic status, household composition, race/ethnicity/language, and housing/transportation), antinuclear antibody (ANA) status and titer, serum PFOA concentration $(\mathrm{ng} / \mathrm{ml})$, and serum PFOS concentration $(\mathrm{ng} / \mathrm{ml})$ from in-person visits from 2003-2019 were included. Spatial overlays were applied to assign census tract identifiers and obtain SVI data for the participants. Statistical analysis using univariate and multivariate linear regression was performed.

Results A total of 81 participants, including 10 patients with SLE and 71 non-SLE controls were evaluated. All were nonHispanic black, $85 \%$ female and $15 \%$ male (table 1). Participants with PFOS exposure had a $30 \%$ increase (worsening) in SVI for every one unit increase in the serum PFOS concentration (95\% CI 0.04-0.60). PFOA concentration was not significantly associated with SVI, 95\% CI -1.63-4.39. Adjusting for SLE, age, and gender, there was no significant association between SVI and PFOS (95\% CI -0.004, 0.70) or PFOA (95\% CI -2.24, 5.08).

Participants with a positive ANA had a statistically significant increase in SVI of $16 \%$ compared to those with a

\begin{tabular}{|c|c|c|c|c|}
\hline & Total $(\mathrm{N}=81)$ & Cases $(\mathrm{N}=10)$ & Controls $(\mathrm{N}=71)$ & $\mathrm{p}$-value \\
\hline Gender & Number $(\%)$ & Number (\%) & Number (\%) & \\
\hline Female & $69(85.2)$ & $9(90)$ & $60(84.5)$ & 0.65 \\
\hline Male & $12(14.8)$ & $1(10)$ & $11(15.5)$ & \\
\hline $\begin{array}{l}\text { Age at visit/sample } \\
\text { collection (years } \pm s d \text { ) }\end{array}$ & $50.6 \pm 14.7$ & $45.4 \pm 13.0$ & $51.3 \pm 12.0$ & 0.24 \\
\hline \multicolumn{5}{|l|}{ Race } \\
\hline Other & $0(0.0)$ & $0(0.0)$ & $0(0.0)$ & \\
\hline African American & $81(100.0)$ & $10(100.0)$ & $71(100.0)$ & \\
\hline \multicolumn{5}{|l|}{ ANA positivity } \\
\hline Yes & $47(58.0)$ & $10(100.0)$ & $37(52.1)$ & 0.004 \\
\hline No & $34(42.0)$ & $0(0.0)$ & $34(47.9)$ & \\
\hline \multicolumn{5}{|l|}{ ANA titer high $(>1: 320)$} \\
\hline Yes & $17(21.0)$ & $8(80.0)$ & $9(12.7)$ & $<0.001$ \\
\hline No & $64(79.0)$ & $2(20.0)$ & $62(87.3)$ & \\
\hline PFOS (ng/ml) & $24.7 \pm 21.8$ & $8.7 \pm 5.4$ & $27.0 \pm 22.2$ & $<0.001$ \\
\hline PFOA (ng/ml) & $3.6 \pm 2.2$ & $2.3 \pm 1.5$ & $3.8 \pm 2.2$ & 0.04 \\
\hline Social vulnerability index & $0.5 \pm 0.3$ & $0.5 \pm 0.4$ & $0.6 \pm 0.3$ & 0.48 \\
\hline
\end{tabular}

negative ANA, 95\% CI 3.17-29.07. There was not a significant difference in SVI between patients with SLE and controls (95\% CI -26.9-12.75).

Conclusion In our study of African Americans with and without SLE, PFOS, but not PFOA, exposure was associated with higher social vulnerability measured by the SVI. ANA positivity was also associated with higher SVI, although SLE diagnosis was not, likely due to the small number with SLE. These findings support continued studies of PFAS and other environmental contaminants which are associated with disparities in exposure, putting vulnerable communities at risk for adverse health impacts such as SLE.

Acknowledgements This work was supported by National Institute of Arthritis and Musculoskeletal and Skin Diseases grants P30AR072582 (JCO), K24AR068406 (DLK), and P30AR072582 (GSG). I would also like to acknowledge the participants in the Systemic Lupus Erythematosus in Gullah Health (SLEIGH) study.

\section{UPDATE ON THE STUDY OF ANTI-MALARIALS IN INCOMPLETE LUPUS ERYTHEMATOSUS (SMILE) CLINICAL TRIAL}

${ }^{1}$ David Karp*, ${ }^{2}$ Nancy Olsen, ${ }^{2}$ Duanping Liao, ${ }^{3}$ Judith James, ${ }^{3}$ Cristina Arriens, ${ }^{4}$ Diane Kamen, ${ }^{5}$ Mariko Ishimori, ${ }^{6}$ Susan Boackle. ${ }^{1}$ University of Texas Southwestern Medical Center, Dallas, TX USA; ${ }^{2}$ Hershey Medical Center, Penn State University, Hershey, PA USA; ${ }^{3}$ Oklahoma Medical Research Foundation, Oklahoma City, OK USA; ${ }^{4}$ Medical University of South Carolina, Charleston, SC USA; ${ }^{5}$ University of Colorado Anschutz Medical Campus, Aurora, CO USA

\subsection{6/lupus-2021-lupus21century.47}

Background There is clear evidence that clinical and laboratory features of systemic lupus erythematosus (SLE) can be present for many years prior to an individual fulfilling the full disease classification criteria. Most commonly, these features include characteristic serologies, but also isolated hematological findings, rash, serositis, or hypocomplementemia. Such individuals may be considered to have 'Incomplete Lupus Erythematosus' or ILE, and some eventually transition to frank SLE over time. There is retrospective evidence that hydroxychloroquine (HCQ) use delayed this progression to SLE. The SMILE trial was undertaken to study the ability of HCQ to prevent progression to lupus in people at risk.

Methods SMILE is an NIH-funded, multi-center, randomized, placebo-controlled study of HCQ in people with an ANA (1:80 by IF) and one or two SLICC criteria for the classification of SLE. Participants can be either sex, ages 15-49, and could not have other definite autoimmune disease or fibromyalgia. The primary end point is the rate of development of new lupus criteria. Subjects are randomized to HCQ or placebo and followed for 24 months or until the development of SLE. Assessments done every 3 months included determination of any new SLICC criteria by history, physical and laboratory, as well as banking of serum, plasma, peripheral blood mononuclear cells, DNA, RNA and urine.

Results Enrollment began in early 2018 and is anticipated to end in the Fall of 2021 with study completion in 2023. Currently, all results remain blinded. As of May 2021, a total of 222 participants were screened and 157 randomized. 31 completed the protocol, 29 were discontinued by clinical staff, and 29 withdrew from the study. 16 participants (10.2\%) developed classification criteria for lupus. The remainder of the participants remain in the study. 352 adverse events 
occurred in 115 subjects; 67 of which were felt to be probably or possibly related to the intervention.

Conclusions Recruitment for a trial of pre-clinical or incomplete lupus is difficult. Barriers included perceived risk of medication for an asymptomatic condition, or desire to take medication, even if not known to work. Nevertheless, a significant number of subjects has transitioned to lupus during the course of the trial. Data comparing HCQ to placebo will be available in 2023.

Acknowledgments This trial is supported by NIH/NIAMS U01 AR071077

Trial Registration ClinicalTrials.gov NCT03030118.

\section{TELEMEDICINE IN RHEUMATOLOGY: A SURVEY OF PATIENT AND PROVIDER SATISFACTION WITH VIRTUAL CARE}

${ }^{1}$ Wei Tang, 'Leila Khalili, ${ }^{2}$ Maria Dall'Era, ${ }^{3}$ Cynthia Aranow, ${ }^{3}$ Meggan Mackay, ${ }^{1}$ Anca Askanase*. ${ }^{1}$ Columbia University Irving Medical Center, Department of Medicine, Division of Rheumatology, New York, NY; 'Lupus Clinic and Rheumatology Clinical Research Center, University of California San Francisco, San Francisco, CA; ${ }^{3}$ Feinstein Institute for Medical Research, Manhasset, NY, 11030

10.1136/lupus-2021-lupus21century.48

Abstract 1105 Table 1 Telemedicine Seven-item Questionnaire

\begin{tabular}{|c|c|c|}
\hline Questionnaire Item & Response & $\mathrm{N}(\%)$ \\
\hline \multirow{5}{*}{$\begin{array}{l}\text { How satisfied were you with your } \\
\text { previous telemedicine visit? }\end{array}$} & Highly satisfied & $50(50 \%)$ \\
\hline & Satisfied & $34(34 \%)$ \\
\hline & Neither satisfied nor unsatisfied & $11(11 \%)$ \\
\hline & Not satisfied & $5(5 \%)$ \\
\hline & Highly unsatisfied & $0(0 \%)$ \\
\hline \multirow[t]{3}{*}{ Reasons for satisfaction? } & Avoid coming into the office & $73(73 \%)$ \\
\hline & Call went smoothly & $77(77 \%)$ \\
\hline & $\begin{array}{l}\text { Decrease their concerns over } \\
\text { condition, medications and risk of } \\
\text { COVID-19 }\end{array}$ & $75(75 \%)$ \\
\hline \multirow[t]{3}{*}{ Reasons for unsatisfaction? } & Technical difficulties & $4(4 \%)$ \\
\hline & Visit was too short & $2(2 \%)$ \\
\hline & Visit was too basic for their needs & $4(4 \%)$ \\
\hline \multirow{5}{*}{$\begin{array}{l}\text { How comfortable were you with your } \\
\text { previous telemedicine visits? }\end{array}$} & Very comfortable & $62(62 \%)$ \\
\hline & Comfortable & $24(24 \%)$ \\
\hline & $\begin{array}{l}\text { Neither comfortable nor } \\
\text { uncomfortable }\end{array}$ & $11(11 \%)$ \\
\hline & Uncomfortable & $3(3 \%)$ \\
\hline & Highly uncomfortable & $0(0 \%)$ \\
\hline \multirow{5}{*}{$\begin{array}{l}\text { The physician was able to address } \\
\text { what was bothering me through the } \\
\text { telemedicine visit? }\end{array}$} & Strongly agree & $54(54 \%)$ \\
\hline & Agree & $37(37 \%)$ \\
\hline & Don't know & $5(5 \%)$ \\
\hline & Disagree & $4(4 \%)$ \\
\hline & Strongly disagree & $0(0 \%)$ \\
\hline \multirow{5}{*}{$\begin{array}{l}\text { Overall, compared to an in-person } \\
\text { visit, the telemedicine visit was? }\end{array}$} & Much better & $10(10 \%)$ \\
\hline & Better & $6(6 \%)$ \\
\hline & Same & $57(57 \%)$ \\
\hline & Worse & $25(25 \%)$ \\
\hline & Much worse & $2(2 \%)$ \\
\hline \multirow{3}{*}{$\begin{array}{l}\text { I would have a telemedicine } \\
\text { appointment in the future, if given } \\
\text { the option. }\end{array}$} & Yes & $77(77 \%)$ \\
\hline & Unsure & $14(14 \%)$ \\
\hline & No & $9(9 \%)$ \\
\hline
\end{tabular}

Background During the COVID-19 pandemic, in-person rheumatology was largely replaced by telemedicine to ensure the safety of both patients and providers. The increased pressure on the healthcare system amidst the pandemic that created a soaring number of patients has pressed an effective supplementary healthcare format for both rheumatology and other specialties. However, it remains unclear whether telemedicine, in the commonly used video-conference format, can serve as a feasible alternative to conventional in-person clinical visits while achieving comparable patient/provider satisfaction and maintaining long-term quality of care. The objective of this study was to evaluate the patient and provider experience with video-conference based virtual care thus provide further information on the prospective use of telemedicine in rheumatology practice.

Methods April-June 2020 we disseminated a seven-item questionnaire to patients with rheumatic diseases who recently attended telemedicine encounters in a video-conference format to evaluate their satisfaction and experience with the encounter. Simultaneously, we surveyed providers who recently conducted virtual care with a similar seven-item questionnaire to evaluate provider attitude towards the virtual care.

Results A total of 100 patients and 17 care providers responded to the survey. Of the 100 patients surveyed, 84 (84\%) reported high levels of satisfaction; 86 (86\%) felt comfortable with the video-conference format and 77 (77\%) expressed willingness to use telemedicine in the future; 92 (92\%) acknowledged that physicians were able to satisfactorily address the issues and concerns that prompted the visit, and $57(57 \%)$ considered the experiences very similar to the inperson clinical visits. However, of the 17 care providers surveyed, only $3(18 \%)$ expressed satisfaction with telemedicine while $14(82 \%)$ considered telemedicine visit worse than conventional in-person clinical visits.

Abstract 1105 Table 2 Demographic characteristics of study subjects

\begin{tabular}{|c|c|c|}
\hline Characteristics & Categories & $\mathrm{N}(\%)$ \\
\hline \multirow[t]{2}{*}{ Gender } & Male & $9(9 \%)$ \\
\hline & Female & $91(91 \%)$ \\
\hline \multirow[t]{6}{*}{ Age (years) } & $20-30$ & $18(18 \%)$ \\
\hline & $30-40$ & $22(22 \%)$ \\
\hline & $40-50$ & $22(22 \%)$ \\
\hline & $50-60$ & $21(21 \%)$ \\
\hline & $60-70$ & $13(13 \%)$ \\
\hline & $70-80$ & $4(4 \%)$ \\
\hline \multirow[t]{4}{*}{ Race } & White & $41(41 \%)$ \\
\hline & Black or African American & $25(25 \%)$ \\
\hline & Asian & $7(7 \%)$ \\
\hline & Hispanic & $26(26 \%)$ \\
\hline Health & Insured & $100(100 \%)$ \\
\hline insurance & Uninsured & $0(0 \%)$ \\
\hline \multirow[t]{8}{*}{ Diagnoses } & Systemic Lupus Erythematosus (SLE) & $60(60 \%)$ \\
\hline & Rheumatoid Arthritis (RA) & $7(7 \%)$ \\
\hline & Undifferentiated Connective Tissue Diseases (UCTD) & $7(7 \%)$ \\
\hline & Psoriatic Arthritis (PsA) & $5(5 \%)$ \\
\hline & Sjogren's Syndrome (SS) & $4(4 \%)$ \\
\hline & Spondylitis & $3(3 \%)$ \\
\hline & Other (Sarcoidosis, Myositis, Osteoarthritis, & $14(14 \%)$ \\
\hline & Fibromyalgia, Uveitis, Vasculitis) & \\
\hline
\end{tabular}

